\title{
Political Obligations and Public Goods
}

\author{
Isaac Taylor ${ }^{1}$ (iD
}

Accepted: 31 December 2020 / Published online: 2 February 2021

(c) The Author(s) 2021

\begin{abstract}
The principle of fairness is a moral principle which states that individuals are under an obligation to contribute towards beneficial cooperative projects. It has been appealed to in arguing that citizens are obligated to pay for public goods that their government supplies. Yet the principle has faced a number of powerful objections, most notably those of Robert Nozick. In responding to some of these objections, proponents of the principle have placed a number of conditions on its application. However, by doing so, they have reduced the number of public goods that the principle can explain obligations to contribute towards, and consequently limited its relevance to questions of political obligation. I argue here that a more permissive version of the principle, with fewer conditions on its application, will perform equally well in responding to Nozick's objections. This opens up the possibility of a theory of political obligation that relies more heavily on the principle of fairness than has previously been thought possible.
\end{abstract}

Keywords Distributive justice $\cdot$ Nozick, Robert · Political obligations · Principle of fairness · Public Goods

\section{Introduction}

Why should we obey the law? In some cases, this is because the law merely requires what morality demands. We should not commit the crime of murder, for instance, because killing people is usually a serious moral wrong. Yet existing states' laws do not merely track independently valid moral requirements in this way. Many governments supply a range of public goods and services-such as national defence, free healthcare, subsidised art projects, national parks, and public roads-and require citizens to make contributions towards them (often financially, through taxation, but sometimes in other ways, such as mandatory service in the armed forces). If there are obligations to obey these sorts of laws, we cannot simply point to the fact that

Isaac Taylor

isaac.taylor@philosophy.su.se

1 Department of Philosophy, Stockholm University, 10691 Stockholm, Sweden 
they coincide with moral obligations that we have anyway. It seems highly suspect that we are under a natural duty to ensure that everyone has access to a national park, for example. If these are genuine obligations, they only appear to exist once the institutions providing public goods are already in place. A different sort of explanation is needed.

A promising way of explaining these sorts of political obligations is by appealing to the principle of fairness. This moral principle says that, under certain circumstances, individuals should contribute towards the production of goods that they benefit from. As citizens generally benefit from the goods and services that their state supplies, this principle, if valid, might explain why citizens are under obligations to follow the states' laws that require contributions towards these goods. But the principle of fairness has faced a number of powerful objections-most notably those of Robert Nozick in Anarchy, State, and Utopia (1974). In response to these objections, those who wish to continue using the principle as a way of explaining political obligations have sought to limit its applicability by placing conditions on the sorts of case in which it can be invoked to ground obligations. Yet in doing so, they have significantly reduced the relevance of the principle to questions of political obligation, as the conditions rule out obligations to contribute towards a wide range of goods that modern governments typically supply.

In this paper, I argue that fewer restrictions on the principle of fairness are necessary. My point of departure from previous discussions is to suggest that some of Nozick's objections will be less convincing once we specify the content of each individual's obligation that the principle assigns. Drawing on an under-analysed but important body of literature on distributive justice and public goods, I argue that if we accept certain plausible limits on how the costs of public goods should be shared, the principle of fairness may be robust in a wider variety of cases. This clears the way for the principle to play a larger role in justifying the political obligations of citizens than many of its proponents think possible.

\section{The Principle of Fairness and Nozick's Objections}

The principle of fairness finds its first detailed exposition in the work of H. L. A. Hart, who refers to it as a principle of 'mutuality of restrictions'. In his words:

When a number of persons conduct any joint enterprise according to rules that restrict their liberty, those who have submitted to these restrictions when required have a right to a similar submission from those who have benefitted by their submission. (Hart 1955, p. 185)

The basic idea here is that when individuals benefit from others taking on certain costs in a cooperative activity ('abiding by rules that restrict their liberty'), those individuals gain obligations to reciprocate by taking on similar costs themselves. Hart thought that this principle was essential to explain why individuals have a prima facie obligation to obey the laws of their state (Hart 1955, p. 185). All 
individuals benefit from their co-citizens obeying the law (through, for example, paying taxes that go towards national defence and policing). The principle thus implies that they are required, as a matter of fairness, to obey those laws as well.

The principle has faced a number of objections. Some of the most significant of these have been put forward by Robert Nozick in Anarchy, State, and Utopia. Nozick provides a set of counter-examples that purport to show that the principle, at least in Hart's formulation, leads to a number of implausible consequences. Two representative counter-examples of this sort are the following:

Book-peddler An individual forces a (good) book into your hand. She then demands payment from you for this (Nozick 1974, p. 95).

PA System 364 of your neighbours set up a public address system that broadcasts across the whole neighbourhood, and each spends one day a year playing records, telling stories, and reading news. You are asked to give up a day to do likewise (Nozick 1974, pp. 93-95).

In both cases, the principle of fairness seems to implausibly imply that you are required to accede to the demands of those who benefit you. And, for Nozick, this shows that the principle is fatally flawed. Those who wish to defend the principle of fairness as a basis for political obligation have responded to Nozick by placing a number of conditions on the principle's application that are designed to rule out obligations being created in cases like Book-peddler and PA System, but not (all) political obligations to contribute towards beneficial government projects.

The first of these conditions that we can consider is designed to rule out obligations in cases like Book-peddler. It states that obligations can only be created through the principle of fairness when:

(i) The benefits received are non-excludable (Arneson 1982, pp. 618-619;

Klosko 1992, pp. 35-37).

A benefit is non-excludable if it is impossible, infeasible, or excessively costly to prevent some people from receiving it once it is produced. The benefits provided by a book are not non-excludable-the benefactor in Book-peddler could quite easily have kept the book to herself. Accepting this condition, then, means that the principle of fairness does not implausibly generate obligations to pay up in this case. In contrast, many of the benefits provided by states for their citizens are non-excludable. It will be practically impossible to exclude some citizens from the benefits of law and order in society once police patrols and a criminal justice system are put in place, for example, since these goods at least to some extent do not protect individuals on a one-by-one basis, but rather provide an environment that ensures each individual is protected. Condition (i) thus still allows us to appeal to the principle of fairness in explaining political obligations.

Serena Olsaretti has argued that condition (i) is too strong. There are many goods that are not non-excludable in the sense outlined above, yet we nonetheless produce in ways that do not exclude individuals from the benefits. She calls these 'socialised goods' (Olsaretti 2013, p. 252). Suppose, for example, that some of 
the benefits of law and order could be made excludable. Individuals could be left to hire their own private security personnel instead of the state providing a police force that ensures the security of everyone. But we might think that this would lead to undesirable consequences: the rich might be able to buy more security than the poor, and thus there would be severe inequalities in personal security. An egalitarian commitment to equal security might lead us to prefer 'socialising' this good. ${ }^{1}$ Olsaretti argues that receipt of socialised goods of this sort, as well as non-excludable goods proper, is capable of generating obligations on the part of those who benefit (Olsaretti 2013, pp. 250-253). She would thus revise (i) in the following way:

(i) The benefits received are non-excludable or in the form of socialised goods.

It is not a concern of this paper to determine whether the principle of fairness should be understood as applying only to strictly non-excludable goods, or whether Olsaretti is correct that socialised goods should also be within its remit. What is clear is that in order to avoid counter-intuitive implications and avoid the principle being applicable to cases like Book-peddler, some condition like this needs to be placed on it. I will therefore state condition (i) as follows:

(i) The benefits are received in the form of public goods.

Where the term 'public goods' can be understood in either of the ways discussed above, according to the reader's preference.

But while this is a necessary condition for obligations to be created, it cannot be sufficient. While it rules out obligations being generated in Book-peddler, it permits them in PA System. The benefits of the PA system are public and, more specifically, non-excludable; it is impossible to prevent any one neighbour hearing the broadcast. Or, at the very least, it would require the neighbours to take onerous steps to do so. And so, the principle of fairness, even when qualified by condition (i), implies that individuals in the neighbourhood are under an obligation to give up a day to operate the PA system. Other conditions are thus needed to avoid this implausible implication.

Why exactly do we find it problematic that a principle generates obligations in $P A$ System? Much of our concern here, I think, stems not so much from the possibility of any obligations being created in such a scheme, but more from the possibility that obligations could be created in particular circumstances. Nozick asks us to imagine versions of the scheme where we do not care much for what is being broadcast, or where our benefit is much less than that of others (Nozick 1974, p. 94). Are we required to give up a day like everyone else in these cases? It seems not, and so the principle of fairness looks problematic even with condition (i) placed on it.

The obvious way of defending the principle of fairness is to add further conditions on its application that rule out obligations in circumstances like those mentioned above. Defenders have converged upon two such conditions:

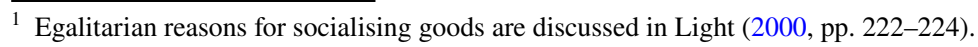


(ii) The costs of fulfilling the obligation generated are less than the benefit one receives from the good (Arneson 1982, p. 621; Klosko 1992, p. 39).

(iii) The costs and benefits involved in producing the good are fairly distributed (Klosko 1992, p. 39; Rawls 1999, p. 122).

While the addition of these conditions may rule out obligations of the sort discussed above - if one did not care much for what was being broadcast, one may not be a net beneficiary and if one benefitted less than others, the scheme as a whole would not be fair-it does not allay Nozick's worries completely. What if, Nozick asks, you would prefer an alternative scheme to be in place? Perhaps you would like the Talmud to be read over the PA system rather than the current entertainment schedule. Or what if you would prefer no scheme in place? Perhaps you would prefer to spend the day you are required to operate the PA system hiking in the mountains, even if this means that there will be no entertainment broadcast all year round. In either case, it still seems problematic to force you to contribute (Nozick 1974, pp. 94-95). Yet both of these scenarios, it seems, could occur in schemes that meet conditions (i)-(iii), and so if the principle of fairness is to be vindicated, it looks like at least one further condition needs to be placed on its application.

Defenders of the principle have generally gone one of two ways in arguing for what this further condition should be. 'Voluntarists' such as John Rawls add the following:

(iv) The benefits from the goods are voluntarily accepted (Rawls 1999, p. 122).

In PA System, you had no choice about whether or not you receive the benefits. Because the broadcast was amplified across the neighbourhood, you could not help but hear it when going about your daily business. And it seems that this is the reason why it is then problematic to hold you under an obligation to contribute. Liberal theorists place a high value on individual autonomy, and consequently are often sceptical about the existence of obligations as a result of factors that one could not have avoided. In contrast to a TV station, which you would have to tune in to benefit from, the benefits of the PA system cannot be avoided. So, while it seems permissible to hold those who watch TV to contribute towards it in some way, for many liberals it is impermissible to hold those who hear the PA broadcast to be under an obligation to pay. This is the intuition that restriction (iv) captures.

George Klosko, a 'non-voluntarist', suggests an alternative condition that can deal with Nozick's PA System. In addition to (i), (ii), and (iii), he argues that genuine obligations can be created if:

(v) The goods that one benefits from are 'presumptively beneficial' (Klosko 1992, p. 39).

The notion of a presumptively beneficial good needs more explanation. As the term suggests, these are goods which 'all members of the community want whatever else they want' (Klosko 1992, p. 40). But not simply this. We can presume that everyone wants a higher income, but this does not make a higher income presumptively beneficial good in the sense that Klosko wants to use the term. For a good to count as presumptively beneficial in the technical sense that he has in mind, 
it must be wanted by all members of the community because it is necessary for a minimally-acceptable life (Klosko 1992, p. 40). Many states supply a number of presumptively beneficial goods, so understood. Klosko lists 'the benefits of physical security provided by law and order, national defence, and protection from a hostile environment' (Klosko 1992, p. 40). He thinks that when individuals receive these sorts of goods, they come under an obligation to contribute towards their continued production, even if they have not accepted them. Receipt of more trivial benefits, like those involved in PA System, however, cannot generate similar obligations. Adding condition (v) to (i)-(iii) thus gets the right result here as well.

While limiting the application of the principle of fairness by adding condition (iv) or (v) enables proponents to avoid implausible implications in examples such as $P A$ System, it does so at a cost. The resulting principle will not only rule out obligations in these examples. It will also be incapable of explaining why we have obligations to contribute towards many of the goods that states typically supply. ${ }^{2}$ For many of these goods are neither accepted by citizens nor presumptively beneficial. Modern governments have a hand in supplying a variety of other sorts of goods, such as well-maintained public areas, scientific knowledge, macroeconomic management, a well-trained workforce, and roads. If the principle of fairness has to be understood as operating with conditions (iv) or (v), though, it appears incapable of explaining why citizens are required to support these projects. Its relevance in explaining why citizens have political obligations becomes severely diminished.

While Klosko (1992, pp. 85-109) has attempted to outline more complex ways in which the principle of fairness, when circumscribed by condition (v), might be used to ground obligations to pay for a wider range of public goods, his efforts either justify relatively few additional obligations (Klosko 1992, p. 98), or else expose him to new objections (Green 1994). Those wishing to offer an account of political obligation that is at least somewhat in line with the demands that existing liberal states make on their citizens have thus either abandoned the principle altogether (Rawls 1971, pp. 336-337), or sought to supplement it with additional principles (Klosko 2005). I will argue below, however, that these manoeuvres are largely unnecessary. We can avoid many of the undesirable results highlighted by Nozick's examples with more minimal limits on the principle of fairness.

\section{Fair Distributions}

As we saw, a number of theorists think that the principle of fairness is only capable of generating obligations when the costs and benefits of beneficial projects are fairly distributed (this was labelled condition (iii)). Yet they often do not set out in any detail what such a fair distribution would look like. This is unfortunate since, as I will suggest in this section, once fairness in the costs and benefits is achieved, the worries that led theorists to add the demanding conditions (iv) or (v) to the principle will disappear, and adding those conditions will thus be shown to be unnecessary.

\footnotetext{
2 This cost of adding condition (iv) is noted in Rawls (1971, pp. 336-337) and Simmons (1979, pp. 136-142). The cost of adding condition (v) is noted in Klosko (1992, p. 85).
} 
How should the costs and benefits of public good production be shared among individuals? Those who have discussed distributive justice in this area tend to distinguish two sorts of public goods (Miller 2004, pp. 136-141; Miller and Taylor 2018, pp. 558-562; Murphy and Nagel 2002, pp. 80-85; Taylor 2014, p. 383). First, there are public goods whose supply is a requirement of justice. Call these 'essential public goods'. Many people think, for instance, that any minimally just state must supply national defence, police protection, and ensure public health, and so would include these on their list of essential public goods. Some might expand this list to include individual health care, tertiary education, and environmental goods.

Important questions need to be answered about how the costs of essential public goods should be shared (if it is done through taxation, whether it should it be at a flat rate or a more progressive schedule, for instance), but we can set aside these issues here. My main concern will be with a second category of public goods. This is because it is likely that contributions towards essential public goods can already be justified without the considerations that I will discuss below. Since these public goods may be required by justice because they are necessary for minimally decent lives (i.e. because they are presumptively beneficial), they will meet condition (v) as well as (i)-(iii), and thus a more restrictive version of the principle of fairness can be invoked here. And even if the category of essential public goods is not completely co-extensive with the category of presumptively beneficial public goods, other principles are likely to be able to be invoked to justify requiring individuals to contribute towards them. A natural duty to support just institutions, for example-which proponents of the principle of fairness often turn to in order to make up the shortcomings of using the principle of fairness in isolation (Klosko 2005, pp. 75-92; Wolff 2000) - would, if valid, explain why individuals are required to do their fair share in all essential public good regimes that apply to them.

I turn, then, to discuss public goods not required by justice, which I will call 'optional public goods'. States regularly produce public goods which, although perhaps hugely beneficial to their citizens, are not plausibly requirements of justice. A state that did not fund parks, public art, museums, and so on may be considered deficient, but most people would not describe this as unjust. It is obligations to contribute towards these public goods that extant theories of political obligation are unlikely to explain. For, however much people value these goods, few appear necessary for minimally acceptable lives. And, since they are by definition not required by justice, appealing to a principle such as the natural duty of justice cannot ground political obligations here.

How, then, should the costs of these optional public goods be distributed across a population? One obvious answer, advocated by a number of authors, is that the costs to each individual should vary with the benefit they receive. More specifically, the costs should be assigned to individuals in proportion to benefit (Miller 2004, pp. 142-143; Murphy and Nagel 2002, p. 85; Taylor 2014, pp. 392-393). ${ }^{3}$ If two people benefit equally from a public good, for example, they should pay the same towards

\footnotetext{
3 While all of these accounts hold that costs should be proportionate to benefit, they differ in two main areas. First, they differ in their specification of how benefits should be distributed (which can be changed
} 
its production; if one benefits twice as much than the other, she should pay twice as much. Call this the 'proportionality requirement'.

Such a requirement might appear out of place with respect to essential public goods. It is often thought that if receipt of a good is a requirement of justice, some people in society can be legitimately asked to pay for it without the promise of a proportionate return. For instance, it might be considered permissible to tax some people to pay for others' expensive medical treatment, even if those being taxed do not have such expensive medical needs, and would be able to pay for their own treatment were they to develop them. ${ }^{4}$ But when we are discussing goods whose supply is not a requirement of justice, asking some individuals to subsidise others without any prospect of a return would appear unfair, as implementing discretionary policies like these should not leave anyone worse off.

Instead, it is plausible to suppose that, if optional public goods are supplied, the costs to each individual should be made proportionate to their benefit. Given that it would not be a moral wrong (or at least not an injustice) to not supply these goods, if states do supply them they must make the arrangement in the interest of everyone to be a part of. Of course, there may be many possible distributions that would be in everyone's interest: an arrangement where one person was barely better off while another benefitted by a disproportionately large amount would be in both of their interests. But adjusting the costs so that they are proportionate to benefit would appear to make the arrangement equally in the interest of everyone: those who get little benefit would be given an equally strong reason as others to cooperate, since they would be required to contribute less. This is the rationale of the proportionality requirement. ${ }^{5}$

The proportionality requirement, however, might be interpreted in two ways. In particular, there are two ways in which we might measure the costs that are to be made proportionate to benefit. First, we might simply look at the contribution that each individual makes: how much money each pays in tax, for example. Call this the 'accounting cost'. Second, though, we might also include in our measurement the opportunity costs to each individual: the foregone benefits that they could receive if

\section{Footnote 3 (continued)}

by supplying additional or alternative public goods). Second, they differ in how the costs should be measured in this calculation, a point that I will return to below.

4 A possible exception comes from David Gauthier's (1986) theory, according to which principles of justice and morality are ultimately to the benefit of all those who abide by them. But since Gauthier's contractarianism would also suggest that the benefits of optional public goods should be proportionate to benefit (Gauthier 1986, pp. 270-272) it is not a counter-example to my main point here.

5 One worry about this requirement is that it would favour the rich, who may not benefit much from public goods because their greater wealth allows them to access private equivalents of public goods. The principle therefore might favour reducing the costs they pay, or else supplying additional public goods that specifically benefit them. While this is a possibility, the concern may be tempered if we assume that the proportionality requirement is only to be applied when there is a just distribution of private goods, as many who put forward versions of it do (Miller 2004, p. 131, n. 4; Murphy and Nagel 2002, p. 85). While those who are justly wealthier may still be favoured, this may look less noxious than in cases of unjust inequalities. When there are unjust inequalities, compensatory measures may need to be made in distributing the costs of public goods. 
Table 1 Public broadcasting

\begin{tabular}{lll}
\hline & Joan & Roberta \\
\hline Benefit & 10 & 10 \\
Payment & 5 & 5 \\
Net Benefit & 5 & 5 \\
\hline
\end{tabular}

they were able to use their contribution in alternative ways. ${ }^{6}$ Call this latter measurement the 'economic cost'. Individuals incurring the same accounting cost from a public good might well incur very different economic costs. If two people are asked to pay the same amount of tax towards a public good, for example, but one would be able to make huge gains in welfare by using the money for private consumption instead, while the second would have nothing else they want to spend the money on, the economic cost to the first would be much higher than to the second.

I want to now suggest that Nozick's worries about the principle of fairness that were discussed above will only arise when the proportionality requirement is understood in the first way, that is, when accounting costs are made proportionate to benefit. These worries, recall, were that such a version of the principle would potentially require people to contribute to cooperative schemes even if they would have preferred alternative schemes, or no schemes, to be in place. If economic costs are made proportionate to benefit, however, such possibilities will not arise-even when the principle is not circumscribed by (iv) or (v).

To see this, imagine two individuals-Joan and Roberta-in a society that produces the public good of public broadcasting. Both benefit equally from this-they each receive 10 units of benefit. Suppose that they are each asked to pay 5 units toward this public good in tax. Suppose also that we can measure benefits and costs in the same units (say the benefits can be expressed as a monetary equivalent). Each would then have a net benefit of 5 units. The resulting distribution can be summarised in Table 1.

Is condition (iii) met in this case? This will depend on how we understand the proportionality requirement. If this requires accounting costs to be made proportionate to benefit, the requirement is clearly met. Both Joan and Roberta incur equal accounting costs (5) and receive equal benefit (10), so these costs are proportionate to benefit for both. The principle of fairness may thus imply that each has an

\footnotetext{
6 The principle of distributive justice for optional public goods defended in Taylor (2014) applies a proportionality requirement in this manner. This 'equal concession principle' (originally discussed in Philippe Van Parijs 2011, pp. 62-64) states that the costs and benefits of these goods should be shared in a way that would be agreed to by all beneficiaries in a hypothetical bargain. And since each individual would, in this hypothetical bargain, take into account the foregone benefits that they would have received in alternative public good schemes, the outcome would involve the benefits they receive from the public good that is supplied made proportionate to economic costs (according to the bargaining model outlined by David Gauthier (1986, pp. 270-272), which this principle relies on). But this is not the only possible principle that would understand the proportionality requirement like this. An alternative, for instance, would require net benefit to be equalised among individuals, where net benefit is measured by the benefits received minus the economic costs. The equal concession principle differs from this one since it might allow inequalities in net benefit.
} 
obligation to contribute here. But such a scheme may be vulnerable to Nozick's objections. Suppose that Roberta would benefit more if a different public good were supplied. Maybe she would benefit by 20 units if her and Joan's contributions were used to fund public parks instead, while Joan is indifferent between these two goods. Or perhaps Roberta would benefit more if no public goods were supplied: perhaps she could spend the 5 units she would save on expensive hiking equipment, and benefit by 20 units by doing so. If either of these is the case, Nozick's concerns about people being bound to cooperative schemes when they would prefer alternative arrangements looks like a problem for the principle of fairness.

But we might instead understand the proportionality requirement in the second way I have suggested: as requiring economic costs being proportionate to benefit. And, if we do this, these Nozickian concerns would not arise. This is because economic costs not only include the payment that each individual makes, but also the foregone additional benefits that each individual could have received from alternative arrangements. Since Roberta would have higher economic costs, owing to her having a higher benefit in alternative arrangements, any arrangement that asks her to pay the same as Joan would not meet the proportionality requirement. The principle of fairness (qualified by condition (iii)), would thus not require her to contribute towards this scheme (at least not by 5 units). ${ }^{7}$

Of course, the complaint that they would be better off without public goods being supplied is not the only one that individuals might make against being asked to contribute towards public goods. Some people might profess preferences for private consumption even though they would objectively be better off when they enjoy public goods (even by their own standards). This might be because they think that this will justify their not paying for a good, or it might simply be an irrational preference. Would these sorts of preferences undermine any putative obligations to pay?

The first thing we can say about this is that an individual cannot nullify their obligations simply because they lie and say that they do not benefit from the public goods in question. Nor do their obligations disappear because of an ill-informed idea that they do not benefit. ${ }^{8}$ The fact that they still do, in fact, benefit appears to be crucial here. For any expressed preferences against the provision of public goods to be morally significant, they cannot be insincere, irrational, or ill-informed. Of course, there may still be people who, thinking clearly and with all relevant information, reject all optional public goods in favour of private consumption. But these cases may be sufficiently rare so that my version of the principle of fairness is still fairly general in application. Those who are not under obligations might be given exemptions. $^{9}$

\footnotetext{
${ }^{7}$ When Roberta would benefit more from private consumption, it would also not meet condition (ii) if this should be understood as requiring benefits to exceed both accounting costs and foregone benefits of private consumption.

${ }^{8}$ Klosko (2014) further argues that various forms of self-deception regarding the benefits of public goods are likewise irrelevant.

${ }^{9}$ Even more restrictive versions of the principle may not be fully general (Klosko 1991, p. 52).
} 
I have shown that if we understand condition (iii) as requiring benefits being proportional to economic costs, the Nozickian objections to the principle of fairness that we have been considering are unsuccessful. If the proportionality principle is applied in a way that takes account of each individuals' opportunity costs, nobody can object that they would prefer an alternative arrangement. Since they would be compensated for the foregone benefits they would have received in any alternative arrangement, existing schemes would be acceptable by their own lights. What I have not shown so far, however, is that opportunity costs should be included in this manner. The way of avoiding Nozick's objections will only succeed if the fair distribution of costs should be understood in the way I have outlined.

But there are good grounds for thinking that this is how a fair distribution of costs should be understood. Indeed, the very reasons we have for adopting the relatively uncontroversial proportionality requirement are also reasons for taking opportunity costs into account when applying that requirement. The reasons for the proportionality requirement, recall, are that it should be in people's self-interest to be involved in optional public good schemes if they are created. And if there is some other arrangement that is a better option for them, being tied to the public good scheme will not be in their interest. The only way of making sure that there is no such arrangement is to take opportunity costs of alternative arrangements into account when allocating costs in the public good scheme.

I have argued, then, that once we explore what is involved in condition (iii), we can avoid some of Nozick's objections without restricting the principle of fairness by the more demanding conditions (iv) or (v). But Nozick's worries about the principle go beyond this. 'You may not decide to give me something, for example a book, and then grab money from me to pay for it', he argues, 'even if I have nothing better to spend my money on' (Nozick 1974, p. 95). The issue, then, is not simply that individuals asked to pay for benefits would prefer alternative arrangements. Rather, Nozick argues that it is illegitimate to require them to contribute even if there are no better alternatives for them. While this is certainly an objection to my version of the principle of fairness, it appears to apply equally to more restrictive versions such as Klosko's: even if we can assume that individuals benefit from presumptively beneficial public goods, this does not answer Nozick's objection that mere receipt of benefits fails to generates reciprocal obligations. Since my aim has been to show that the concerns that animated Klosko and others do not, in fact, necessitate the more stringent conditions that they place on the principle of fairness, and not to answer all possible objections to the principle, this problem can be set aside.

\section{Political Obligations}

Some theorists have made similar arguments: they assert that conditions like (iv) and (v) do not need to be met for obligations to be created by the receipt of benefits (Cullity 1995; Wolff 1995). While I think that these authors' arguments face problems, I will not offer a full criticism of them here. Rather, my aim is to consider a response that has been offered by Klosko to these sorts of arguments, which defends 
the necessity of more demanding conditions like (v). Since this response appears to tell against my own approach as well, it will be useful to outline a rebuttal.

Jonathan Wolff, contra Klosko, denies that one can only be under obligations to support presumptively beneficial public goods that one involuntarily benefits from (Wolff 1995). For Wolff, so long as one is a net beneficiary of a public good scheme after one has made the necessary contribution, one can be under an obligation to contribute, irrespective of whether the good is presumptively beneficial or not: 'obligations are generated for an individual only if an individual receives a net benefit according to his or her subjective scale of valuation' (Wolff 1995, p. 96).

There are a number of possible responses to this view. As we saw earlier, Nozick's counter-examples seem to show that obligations to contribute are not only questionable when one is not a net beneficiary of a scheme, but also when one is a net beneficiary, yet would benefit from another scheme, or no scheme being in place, even more. I argued in the previous section that Nozick's worries in this respect are misplaced. Klosko, however, responds to Wolff in a different way. He does not object to the idea that one can be under moral obligations to contribute towards public goods that are not presumptively beneficial. But he does hold that one cannot be under a political obligation to do so. To see why, we need to investigate the features of political obligations that do not attach to other sorts of moral obligations.

To begin with, political obligations provide what I will call content-independent reasons for action. ${ }^{10}$ By this, I mean that the reasons to comply with political obligations are, in a certain sense, independent of the actions required by those obligations. Not all obligations are of this sort; the obligation not to kill people, for example, provides reasons for action because not killing people is the morally right thing to do. But some are, like the obligation to keep a promise. If I promise to pay you $£ 10$, I should pay you the money not because it is a good thing to do in general, but simply because I have promised to do so. Likewise with political obligations: if a state tells its citizens to drive on the right-hand side of the road, they may be under an obligation to do so. This would not be because driving on the right is intrinsically better than driving on the left, but rather because following the state's directives will ensure that traffic proceeds efficiently, there will be fewer accidents, and so on.

Despite the obligation to keep a promise and political obligations both being content-independent in this sense, they differ in that the latter, but not the former, have content that is fixed by an agent other than the one under the obligation. The obligation to keep a promise is fixed by the promiser. If I promise to pay you $£ 10, \mathrm{I}$ am committed to handing over $£ 10$ to you; if I promise $£ 20$ I must surrender $£ 20$. The content of what I have to do is within my control. This is not true of political obligations. If a government tells citizens to drive on the right-hand side of the road, and they have an obligation to do so, then they are under an obligation whose content

\footnotetext{
$\overline{10}$ Klosko (2011) has argued that political obligations do not provide a particular sort of content-independent reason for action, namely that one should obey the law simply because it is the law. However, his argument is consistent with the view that political obligations do provide other sorts of content-independent reasons for action, as I explain this idea here (although Klosko might not call these reasons "content-independent', given how he defines that term).
} 
they have no control over (except, perhaps, through democratic mechanisms-but this really is not control in a relevant sense, given how unlikely one is to affect the outcome of a democratic decision).

All this might also apply to political obligations to contribute towards public goods that the state supplies. A state might supply a number of different packages of public goods, but in each case citizens may be thought to be obligated to support these. One state might provide more public parks, for instance, another might choose to build public museums on its empty land instead. If citizens of both states have political obligations to contribute towards the goods that their state supplies, these are content-independent in that they are required to contribute irrespective of what they are being asked to contribute towards. Merely living in one state or another will determine whether one is required to pay for parks or museums. And the exact content is not chosen directly by each individual citizen, but by their governments.

What gives a government a right to choose one package of goods over another and expect citizens to contribute towards it? If we find the principle of fairness plausible, we would think that, so long as certain conditions are met, governments can indeed generate obligations on the part of their citizens by providing goods. Which conditions? First, the goods in question must be public (condition (i)). When individuals are provided with private goods that could easily be withheld from them, there is little reason for requiring payment; we could allow the supplier of these goods to sell them in a market transaction instead. In addition to these, says Wolff, so long as each individual is a net beneficiary of the scheme (condition (ii)) and is only asked to pay their fair share (condition (iii)), there is no reason not to hold individuals under an obligation to pay.

Klosko disagrees. It would be impossible in practice, he argues, to know how much individuals benefit from schemes that supply public goods that are not presumptively beneficial. Individuals' tastes for these sorts of goods differ, and we cannot expect to know by how much each values the good in question (Klosko 1998, p. 62). This is significant for two reasons. First, it will often be difficult to know that an individual really is a net beneficiary from a public good scheme (and so to know whether principle (ii) is met) (Klosko 1998, pp. 62-63). Second, it makes determining a fair distribution of costs more difficult. If we think that the costs of public good schemes for each individual should be influenced by how much they benefit (which the proportionality requirement requires, for example), then it will be difficult to know how to distribute the costs in order to ensure that the public good scheme meets condition (iii). 'In practical terms', says Klosko, 'there is no alternative but to allow [each individual] to make this determination herself and take her word for it' (Klosko 1998, p. 63). Since a state cannot be sure that it is supplying public goods in line with conditions (ii) and (iii), it cannot generate genuine obligations on the part of citizens whose content it determines.

These problems are lessened, according to Klosko, when the public goods being supplied are presumptively beneficial. The high level of benefit associated with these goods means that states can be fairly sure that everyone will be a net beneficiary after they have paid the necessary costs. And because people's preferences for presumptively beneficial public goods are likely to be more uniform (most people value national defence highly, for instance, which cannot be said for optional public 
goods such as national parks, which any two different individuals are likely to value differently depending on their tastes), governments can assume that everyone benefits equally, and take this into account when attempting to determine a fair distribution of costs (Klosko, 1998, p. 63). It seems, then, that only when a government supplies presumptively beneficial public goods can it generate genuine political obligations - that is, obligations that are both content-independent and determined by agents other than those under the obligations in question.

However, I think that a state that supplies a package of public goods that are not presumptively beneficial may be sufficiently confident that all individuals are net beneficiaries from that package (meeting condition (ii)), and they can ensure a fair distribution of the costs and benefits of the package (meeting condition (iii)), and therefore impose genuine political obligations on citizens.

There are two things to say regarding condition (ii). First, we might be fairly sure that each individual is a net beneficiary from a single public good being supplied, even if the good is not essential for a minimally decent life. Some of these goods provide important benefits which individuals have fairly uniform preferences for. It is likely, for example, that even when individuals have a sufficient level of physical security to function normally, they will benefit from government actions that increase their security above this minimum. Some operations aimed at preventing terrorist attacks, for example, at least when the costs that individuals are being asked to take up are relatively minor (such as being subject to some form of unintrusive surveillance), are likely to leave everyone a net beneficiary. ${ }^{11}$

Second, even if an individual may not benefit from some of these public goods when taken in isolation, we can be fairly sure that once a package of discretionary public goods is supplied, each will benefit sufficiently. ${ }^{12}$ While supplying a greater range of public goods opens up the possibility of some individuals preferring alternative arrangements, it is possible that a package of goods that catered for a diversity of tastes could be supplied in a way that renders each individual as well off as they could be when compared to feasible alternatives. (This will certainly be true in more culturally homogenous societies, where a low number of different public goods may be needed to cater for different tastes.)

I move on, then, to how condition (iii) might be met. While it is true that we may not have an exact measure of how much each and every individual benefits from a public good (or a package of public goods), we can often make reliable estimates and vary the costs accordingly to ensure an acceptably fair distribution. Indeed, the whole discipline of welfare economics aims precisely at identifying the winners and losers from different government actions. It has long been noted, for instance, that inequalities in private goods tend to lead to unequal benefit from public goods. In some cases, this is because a prerequisite to one's benefitting from public goods is

\footnotetext{
11 Even if some individuals would object to any sacrifice to provide security-for example, any information being shared with their government under any conditions-my arguments in the previous section suggest that if these preferences are ill-informed, insincere, or irrational, they do not nullify obligations.

12 Arguments that the principle of fairness will do a better job in justifying obligations to contribute towards packages of public goods have previously been made by den Hartogh (2002, pp. 62-90) and Klosko (2005, pp. 102-103), although these are different from the argument that I will make here.
} 
being in possession of certain resources: car owners will benefit more from non-car owners from public roads, for example. In other cases, the ways in which benefits are distributed are more diverse, but still identifiable. Thus, middle-class individuals get more out of appointments with doctors-who are largely from middle-class backgrounds themselves - owing to their feeling more comfortable asking questions and making demands from people whom they view as similar to them (LeGrand 1982). ${ }^{13}$ In either case, we can know how the benefits of public goods fall across different sections of a population. Armed with this data, we can easily vary costs to make them at least roughly proportionate to benefit: we might exempt non-car owners from a road tax, for example, or we might pay for public healthcare through a progressive taxation scheme in which middle-class individuals pay more. ${ }^{14}$

Of course, these policies are somewhat blunt; we are unlikely to be able to ensure that the costs and benefits correspond exactly to whatever principle we think describes a fair distribution (such as my own preferred equal concession principle). But we may nonetheless be able to approximate one to a sufficient extent for obligations to be generated. Nozick's concerns about the creation of obligations in unfair schemes seem to tell most strongly against the principle of fairness in grossly unjust schemes where the injustice is the result of intentional design. I think that we would be more willing to think that obligations are created in schemes that although not being perfectly just, sufficiently approximate a just distribution. This is particularly true when condition (ii) is met, and everyone is a net beneficiary of a package of public goods.

My preferred version of the principle of fairness, then, appears capable of generating political, and not simply moral, obligations. A state can supply a package of optional public goods in a way in which it can be fairly sure that all of its citizens are net beneficiaries from, and in a way that at least approximates a fair distribution of costs.

\section{Conclusion}

Some of Nozick's objections to the principle of fairness - in particular, his worries that it might bind individuals to cooperative schemes when they would prefer alternative arrangements-have led many proponents of it to modify it in ways that limit its relevance to questions of political obligation. I have argued here that these modifications are unnecessary: more minimal conditions on the principle will be sufficient to avoid the objections.

\footnotetext{
${ }^{13}$ Using objective measures such as time spent on the road or time in doctor's appointments, along with some assumptions about how much benefit is received in a given time, may be preferred because it will ensure that insincere, irrational, or ill-informed preferences are not used as indicators of benefit.

${ }^{14}$ For additional proposals for how we can ensure a fair distribution of costs, see Miller and Taylor (2018, p. 572).
} 
There are, of course, other objections to the principle (including one by Nozick himself, which was mentioned earlier). ${ }^{15}$ But, insofar as these apply to all versions of it, they are not my concern here. My aim has been to show that the perceived problems with the principle that led theorists such as Klosko and Rawls to place more stringent limits on it (and thus reduce its utility in a theory of political obligation) can be avoided even with a less restrictive version. This is the first step in developing a more satisfactory theory of political obligation based on the principle of fairness than has previously been put forward.

Acknowledgements I would like to thank audiences at the University of Minho and the University of Colorado Boulder, and especially David Boonin and Ben Bryan, for very helpful discussions of this paper. I am also grateful to two anonymous reviewers for their suggestions.

Funding Open Access funding provided by Stockholm University.

Open Access This article is licensed under a Creative Commons Attribution 4.0 International License, which permits use, sharing, adaptation, distribution and reproduction in any medium or format, as long as you give appropriate credit to the original author(s) and the source, provide a link to the Creative Commons licence, and indicate if changes were made. The images or other third party material in this article are included in the article's Creative Commons licence, unless indicated otherwise in a credit line to the material. If material is not included in the article's Creative Commons licence and your intended use is not permitted by statutory regulation or exceeds the permitted use, you will need to obtain permission directly from the copyright holder. To view a copy of this licence, visit http://creativecommons.org/licen ses/by/4.0/.

\section{References}

Arneson, Richard J. 1982. The Principle of Fairness and Free-Rider Problems. Ethics 92(4): 616-633.

Cullity, Garrett. 1995. Moral Free Riding. Philosophy and Public Affairs 24(1): 3-34.

den Hartogh, Govert A. 2002. Mutual Expectations: A Conventionalist Theory of Law. The Hague: Kluwer Law International.

Gauthier, David. 1986. Morals by Agreement. Oxford: Oxford University Press.

Green, Leslie. 1994. Review of The Principle of Fairness and Political Obligation. Ethics 104(2): 392-394.

Hart, H. L. A. 1955. Are there any Natural Rights? The Philosophical Review 64(2): 175-191.

Klosko, George. 1992. The Principle of Fairness and Political Obligation. Lanham, MD: Rowman \& Littlefield.

Klosko, George. 1998. Fixed Content of Political Obligations. Political Studies 46(1): 53-67.

Klosko, George. 2005. Political Obligations. Oxford: Oxford University Press.

Klosko, George. 2011. Are Political Obligations Content Independent? Political Theory 39(4): 498-523.

Klosko, George. 2014. Fairness, Obligations, and Non-acceptance of Benefits. Political Studies 62(1): 159-171.

LeGrand, Julian. 1982. The Strategy of Equality: Redistribution and the Social Services. London: George Allen and Unwin.

Light, Andrew. 2000. Public Goods, Future Generations and Environmental Protection. In Anatole Anton, ed. Milton Fisk and Nancy Holmstrom, 209-225. Boulder, CO: Westview Press: Not for Sale. In Defense of Public Goods.

McDermott, Daniel. 2004. Fair-Play Obligations. Political Studies 52: 216-232.

${ }^{15}$ For others, see McDermott (2004) and Zhu (2015). 
Miller, David. 2004. Justice, Democracy, and Public Goods. In Justice and Democracy: Essays for Brian Barry, ed. K. Dowding, R. E. Goodin, and C. Pateman, 127-149. Cambridge: Cambridge University Press.

Miller, David, and Isaac Taylor. 2018. Public Goods. In The Oxford Handbook of Distributive Justice, ed. S. Olsaretti, 556-575. Oxford: Oxford University Press.

Murphy, Liam, and Thomas Nagel. 2002. The Myth of Ownership: Taxes and Justice. Oxford: Oxford University Press.

Nozick, Robert. 1974. Anarchy, State, and Utopia. Oxford: Blackwell.

Olsaretti, Serena. 2013. Children as Public Goods? Philosophy \& Public Affairs 41(3): 226-258.

Rawls, John. 1971. A Theory of Justice. Cambridge, MA: Harvard University Press.

Rawls, John. 1999. Legal Obligation and the Duty of Fair Play. In Collected Papers, ed. S. Freeman, 117-129. Cambridge, MA: Harvard University Press.

Simmons, A. J. 1979. Moral Principles and Political Obligations. Princeton: Princeton University Press.

Taylor, Isaac. 2014. Language as a Global Public Good. Res Publica 20(4): 377-394.

Wolff, Jonathan. 1995. Political Obligation, Fairness, and Independence. Ratio (New Series) 8(1): 87-99.

Wolff, Jonathan. 2000. Political Obligation: A Pluralistic Approach. In Pluralism: The Philosophy and Politics of Diversity, ed. M. Baghramain and A. Ingram, 179-196. London: Routledge.

Zhu, Jiafeng. 2015. Fairness, Political Obligation, and the Justificatory Gap. Journal of Moral Philosophy 12(3): 290-312.

Publisher's Note Springer Nature remains neutral with regard to jurisdictional claims in published maps and institutional affiliations. 